\title{
PROPOSTA DE ENSINO-APRENDIZAGEM APLICADA A ARQUITETURA DE INTERIORES
}

\author{
LOUREIRO, Priscilla Silva \\ Universidade Vila Velha, e-mail: priscilla.loureiro@uvv.br \\ SANTOS, Laila Souza \\ Universidade Vila Velha, e-mail: laila.santos@uvv.br \\ RAMOS, Larissa Letícia Andara \\ Universidade Vila Velha, e-mail: larissa.ramos@uvv.br \\ MUNIZ, Andreia Fernandes \\ Universidade Vila Velha, e-mail: andreia. muniz@uvv.br
}

\begin{abstract}
RESUMO
Arquitetura e Planejamento de Interiores é uma disciplina que contempla uma das atribuições profissionais mais exercidas pelos arquitetos, com relevância na inserção de recém-formados no mercado. Embora essencialmente prática, possui carga horária reduzida se comparada a outras disciplinas projetuais do currículo. Este artigo objetiva descrever iniciativas na promoção da interdisciplinaridade entre essa e outras disciplinas do curso e relatar a experiência acumulada, que utiliza a metodologia de sala de aula invertida e integra novas tecnologias de informação e comunicação com vistas a melhorar o aproveitamento do tempo de aula, potencializar a prática e estimular o envolvimento do aluno. Como estratégias utilizadas, enfatiza-se o uso de redes sociais como ambiente de ensino e meio de comunicação, o que possibilita trabalhar a teoria e apresentação de resultados preliminares fora do ambiente de aula, permitindo que os encontros presenciais sejam direcionados à orientação dos projetos. Buscando promover a aproximação com o mercado, os alunos têm contato com clientes reais, utilizam ferramentas como vídeo e site para a apresentação dos resultados e recebem avaliação de seus clientes e professores. Observou-se que a metodologia utilizada melhora o desempenho dos alunos, tornam a sala de aula produtiva e permitem a aproximação com a realidade de mercado.
\end{abstract}

Palavras-chave: Arquitetura de interiores, Metodologia Ativa, Sala de aula invertida, Projeto.

\begin{abstract}
Architecture and Interior Planning is a discipline that contemplates one of the most professional attributions practiced by architects, relevant on the insertion of new graduates in the market. Although essentially practical, it has a shorter workload compared to other curricular design disciplines. This article aims to describe initiatives in the promotion of interdisciplinary between this and other subjects and to report the experience accumulated in this discipline, which makes use of inverted classroom methodology and integrates new information and communication technologies into the educational process with a view to improving the use of class time, enhancing practice and stimulating student involvement. As some of the strategies, emphasis is placed on the use of social networks as a teaching environment and means of communication, which makes it possible to work on theory and presentation of preliminary results outside the classroom environment, thus allowing face-to-face meetings to be directed towards project orientation. Seeking to promote the approach to market practice, students have contact with real clients, use tools such as video and website to present results and receive evaluation of their clients and teachers. It was observed that this methodology improves the performance of students, makes the classroom productive and allows the approximation with the reality of the market.
\end{abstract}

Keywords: Interior architecture, Active Methodology, Flipped Classroom, Project

LOUREIRO, P. S.; SANTOS, L. S.; RAMOS, L. L. A.; MUNIZ, A. F. Proposta de ensino-aprendizagem aplicada a Arquitetura de Interiores. In: SIMPÓSIO BRASILEIRO DE QUALIDADE DO PROJETO NO AMBIENTE CONSTRUÍDO, 6., 2019, Uberlândia. Anais... Uberlândia: PPGAU/FAUeD/UFU, 2019. p. 1599-1606. DOI https://doi.org/10.14393/sbqp19144. 


\section{A DISCIPLINA}

Arquitetura e Planejamento de Interiores integra a matriz curricular do curso de Arquitetura e Urbanismo da Universidade Vila Velha-ES, sendo oferecida no $5^{\circ}$ período e propondo-se a trabalhar, especificamente, projetos de ambientes internos. A disciplina, com carga horária de 80h, é ministrada em turmas de até 25 alunos por dois professores: um na condição de professor gerente e outro na de professor consultor. No decorrer do semestre, os alunos desenvolvem dois projetos em que experimentam alguns dos principais desafios atuais da arquitetura de ambientes interiores: reformar um apartamento compacto e criar espaços de trabalho contemporâneos.

Até a implantação da metodologia apresentada neste artigo, havia certa insatisfação por parte dos alunos e professores quanto à dificuldade de se trabalhar todo o conteúdo teórico e prático para o desenvolvimento e orientação de dois projetos em um único semestre letivo, tendo em vista a reduzida carga horária disponível. Com alguma frequência os trabalhos eram desenvolvidos com pouco aprofundamento teórico e/ou prático, apresentavam soluções conceituais ou executivas incipientes e, por vezes, os alunos abandonavam os projetos para se dedicarem a outras disciplinas.

A partir deste diagnóstico, que considerou a opinião de alunos e professores envolvidos na disciplina ao longo de 6 semestres consecutivos, percebeu-se que a orientação prática dos projetos era a principal demanda. Ainda no contexto da sala de aula, a exposição de resultados das pesquisas à turma, tais como estudos de caso, e a explanação da teoria projetual ocupavam um tempo que poderia ser redirecionado. A experiência demonstrou a necessidade de incrementar o tempo dedicado às orientações práticas de projeto, de modo a potencializar a prática, aprofundar a qualidade das propostas de projeto e, assim, possibilitar melhores resultados.

Considerando-se que o desenvolvimento de projetos de arquitetura de interiores é uma das atribuições profissionais mais exercidas pelos arquitetos, sendo importantes na inserção de recém-formados no mercado de trabalho, identificou-se a necessidade de aprimoramento e atualização da metodologia de ensino de forma a incorporar abordagens capazes de atender inclusive às demandas de uma geração de alunos considerados, por alguns autores, nativos digitais.

Buscou-se, para isso, embasamento teórico na metodologia de sala de aula invertida (SUHR, 2016), uma abordagem ativa de ensino e aprendizagem, mais centrada na figura do aluno que na figura do professor, fundamentada na construção e na descoberta do conhecimento e que incentiva a aprendizagem permanente e personalizada.

A metodologia implementada na disciplina visou contemplar o desenvolvimento das competências e habilidades presentes nas Diretrizes Curriculares Nacionais do curso de graduação em Arquitetura e Urbanismo (BRASIL, 2010) e também nas Diretrizes Gerais do ENADE (BRASIL, 2014). Estabeleceu-se, ainda, como objetivo da nova metodologia, a utilização de novas tecnologias de informação e comunicação ao processo de ensinoaprendizagem, adoção de atividades focadas na prática projetual, na interdisciplinaridade (integração de disciplinas no mesmo período), na transdisciplinaridade (integração de disciplinas de diferentes períodos), no contato com o mercado, na cooperação e argumentação. 
A seguir é relatada a experiência acumulada nesta disciplina, incluindo a metodologia e as estratégias que vem sendo utilizadas atualmente, bem como os resultados obtidos.

\section{METODOLOGIA DE ENSINO-APRENDIZAGEM}

$\mathrm{Na}$ metodologia implementada, a teoria incorpora-se ao máximo às orientações, reduzindo-se o tempo com explanações coletivas muito prolongadas. A teoria é colocada de forma breve e o aluno é incentivado a realizar estudos de casos, buscar referências e exemplos de aplicações práticas dos conceitos teóricos, sendo os conteúdos resultantes dessas pesquisas compartilhados em rede social.

Para lidar com a diversidade e estimular o autodesenvolvimento foi proposto o uso do Facebook como ferramenta de comunicação e plataforma para compartilhamento das atividades e debates, como uma extensão de sala de aula, de forma a liberar os encontros para tutoria e aproximar o método à linguagem e à realidade desta geração de estudantes. O grupo criado na rede funciona como um estímulo ao autodesenvolvimento, em que cada aluno colabora na construção do conhecimento coletivo ao alimentar um banco de dados e referências compartilhado e acessível à turma (Figura 1)
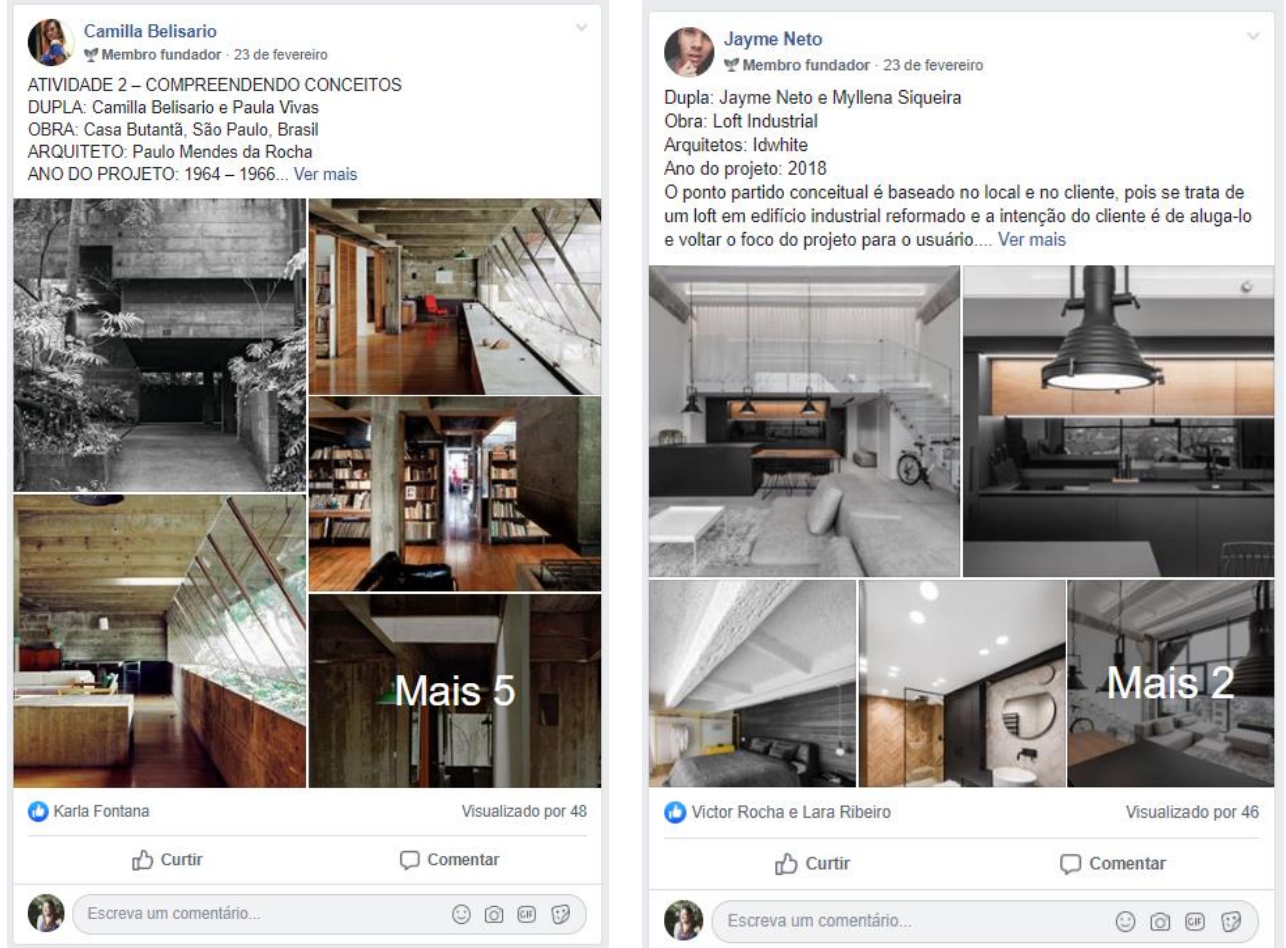

Figura 1 - exemplos de postagens dos alunos elaboradas com base em pesquisas

Fonte: Grupo fechado da disciplina no Facebook

Esta interface, embora possivelmente disperse uma parcela dos estudantes, permite ampliar o tempo de envolvimento do aluno com a disciplina ao permitir a consulta aos trabalhos próprios e dos colegas conforme as demandas individuais. Sua utilização libera os encontros de aula para orientações, desenvolvimento de projeto e visitas guiadas em lojas de produtos e parceiros do ramo de interiores, sendo adotada atualmente como 
ferramenta indispensável para o desenvolvimento da proposta de sala de aula invertida.

Os trabalhos propostos visam promover a interdisciplinaridade. Conteúdos de teoria e história da arquitetura e urbanismo e personalidades relevantes da área são revisitados com objetivos de implementar alguns de seus conceitos em projeto. As estratégias específicas para retomar esses conteúdos estão descritas em mais detalhes no item Projeto 01: reforma em apartamento compacto.

Ao longo de todo o semestre os alunos são incentivados a utilizar softwares de desenvolvimento de projetos CAD e BIM, oferecendo uma aprendizagem continuada e transdisciplinar, com ênfase no uso de ferramentas de computação gráfica aprendidos no semestre anterior. Para permitir que isso ocorra de forma consistente, a professora da disciplina de Informática participa como assistente nas orientações de projetos de interiores. Essa iniciativa atende às habilidades e competências relacionadas à capacitação dos estudantes para estágios e sua posterior inserção no mercado, na produção de projetos técnicos, conhecimento aplicado de softwares, como Autocad e Revit Architecture, e formatação para apresentação profissional.

Inclui-se, ainda, no segundo projeto, a figura do cliente real, com quem o aluno tem contato em momento externo à sala de aula, renovando o estímulo para desenvolver o segundo projeto e estreitando a relação com o mercado. Essa estratégia é descrita posteriormente, no Projeto 02: espaços de trabalho contemporâneos.

A seguir são apresentadas as atividades contempladas na metodologia proposta, detalhando-se as estratégias utilizadas na disciplina.

\subsection{Projeto 1: reforma em apartamento compacto}

Devido ao crescimento urbano e valorização imobiliária, tornaram-se mais constantes e impactantes as reformas em edificações existentes, proporcionando crescente demanda aos escritórios de arquitetura. Outra possibilidade de atuação profissional diz respeito a projetos de interiores residenciais, sobretudo de apartamentos compactos, largamente produzidos no Brasil nas últimas décadas.

Partindo desta premissa mercadológica, selecionou-se como primeira proposta de trabalho a reforma em apartamento compacto. O projeto 01 é então dividido em módulo de pesquisa e projeto. O módulo de pesquisa tem como objetivo proporcionar embasamento teórico de composição e projeto, resgatar o estudo de importantes nomes e obras apresentadas em disciplinas anteriores e desenvolver capacidade crítica e argumentativa.

Cada aluno ou dupla deve desenvolver um projeto de interiores considerando - legado ou conceito da obra de uma personalidade na área de arquitetura, tal como Oscar Niemeyer, Mies Van der Rohe, Lina Bo Bardi, Tadao Ando, Frank Gehry, dentre outros, sugeridos pelo professor. O exercício incentiva o aluno a revisar produções de destaque e proporciona o resgate do conhecimento a cerca de diferentes linguagens artísticas-projetuais, promovendo a transdisciplinaridade, uma vez que os grandes nomes e as principais vertentes da teoria e história da arquitetura e urbanismo são estudados em períodos anteriores. Isso enriquece o repertório dos alunos, 
fundamenta argumentação e melhora a qualidade das propostas. As pesquisas acerca das personalidades e suas diferentes linguagens artísticas e projetuais geram postagens no grupo do Facebook (Figuras 1 e 2) e permitem a comparação dessas linguagens, a troca e amadurecimento das ideias.

O módulo de projeto visa o desenvolvimento da proposta conceitual e técnica para reforma do apartamento. São inicialmente identificadas a linguagem e/ou estratégias de projeto comumente utilizadas pela personalidade pesquisada, e produzidas, com base nisso, a ambientação, as plantas baixas de alvenarias e divisórias, paginação de revestimentos, projeto de forro, luminotécnico, indicação de alterações de pontos elétricos, antena, lógica, hidrossanitários e gás, detalhamentos executivos e outros relacionados à etapa completa de obra.

\subsection{Projeto 2: Espaços de trabalho contemporâneos}

A escolha por trabalhar a temática dos espaços de trabalho fundamenta-se, por um lado, com a pertinência do tema e dos efeitos diretos do projeto de arquitetura de interiores em aspectos ligados à qualidade espacial, ergonomia, conforto e produtividade dos usuários que, com frequência, permanecem nestes espaços por tempos prolongados. Por outro, há também a possibilidade de conexão interdisciplinar com a temática abordada na disciplina de Ateliê de Projeto 3, em que os alunos desenvolvem um edifício híbrido vertical, que abriga, dentre outros, o uso comercial.

Os alunos são orientados a escolher um conjunto de salas comerciais ou pavimento corporativo pertencente ao edifício desenvolvido por eles mesmos na disciplina de Ateliê e, elaboram, na disciplina de Arquitetura e Planejamento de Interiores, os espaços de trabalho a serem implementados nestes ambientes. Sugere-se o desenvolvimento de projetos como sedes de empresas de médio e pequeno porte, escritórios de contabilidade, advocacia, publicidade, engenharia, dentre outros.

A interdisciplinaridade do exercício oportuniza que os alunos planejem soluções para um mesmo espaço em diferentes escalas. Ou seja, os alunos têm claras as condicionantes externas que os levaram a projetar o espaço comercial escolhido - que está contido no edifício como um todo e que se define a partir de soluções para as circulações verticais e horizontais, áreas técnicas, elementos estruturais, esquadrias, questões de incidência e proteção solar, acesso às vistas e etc. - e posteriormente, experimentam projetar os interiores deste ambiente, ou seja, enfrentam o desafio de solucionar questões espaciais e construtivas cujas condicionantes internas, dessa vez, foram por eles mesmos colocadas.

A atividade proposta no Projeto 2 é, tal como a anterior, dividida em módulos de pesquisa e projeto. A pesquisa visa aprofundar os conhecimentos relacionados à concepção de espaços coorporativos ao englobar o estudo de bibliografia específica (MEEL; REE, 2014) e estudo de caso de espaço de trabalho. Os resultados do módulo de pesquisa 2 são novamente compartilhados em rede e colaboram na construção do conhecimento coletivo.

Ainda na etapa de pesquisa, o aluno enfrenta uma situação real de abordagem com o cliente. Essa situação é realizada ao definir-se, primeiramente, o uso específico do espaço de trabalho que se pretende 
projetar (ex.: escritório de contabilidade) e identificando-se um profissional com experiência na área, que fará o papel de cliente. Posteriormente os alunos realizam uma entrevista com o profissional a fim de identificar as demandas espaciais objetivas em termos de espaços, população, equipamentos, fluxos, e etc., e de captar eventuais necessidades subjetivas específicas da atividade profissional em questão, formando, por fim, um quadro sintético: o briefing.

Tomando como base os produtos da pesquisa, é desenvolvido um diagrama de setorização, posicionando os ambientes definidos pelo briefing no ambiente comercial escolhido e na sequência se desenvolve o projeto conceitual e técnico para espaço de trabalho no tema definido pelos alunos.

A apresentação conceitual da proposta ocorre através de um site criado pelo aluno, integrado à disciplina de ateliê de projetos, com o formato de divulgação de empreendimento, conforme padrão de mercado. Além de apresentarem seus projetos conceituais em sala aos colegas, os alunos devem apresentá-lo também ao "cliente" definido na etapa anterior, filmar suas considerações e compartilhar no grupo do Facebook. Este módulo proporciona a aprendizagem prática ativa e simula uma apresentação em formato profissional para vários clientes reais, aproximando o aluno à prática do mercado.

\section{RESULTADOS ALCANÇADOS}

O modelo de sala de aula invertida utilizado nesta disciplina proporciona a aplicação de uma proposta de ensino aprendizagem mais ativa, otimizando não só o tempo de orientação em sala, mas ampliando o tempo de envolvimento do aluno com o projeto.

As competências e habilidades necessárias para conceber projetos de arquitetura são desenvolvidas em todas as etapas de modo lógicosequenciado, bem como o domínio relacionado à gestão, coordenação, planejamento e compatibilização, pois o modelo de sala de aula invertida demanda envolvimento e comprometimento por parte dos alunos, não apenas do professor, o que faz com que precisem se organizar e trabalhar de forma colaborativa e integrada.

Habilidades relacionadas à argumentação e avaliação de consequências são testadas ao limite com a participação também de um membro externo, o cliente. Segundo relatos dos próprios alunos, tanto a participação quanto a construção do site aproximam o estudante de uma experiência real, possibilitando a criação de portfólio e repertório projetual e capacitando para os estágios supervisionados.

As ações integradas criam uma conjuntura favorável à criatividade, pesquisa, prática, argumentação, análise, cooperação e autodesenvolvimento entre os estudantes. Estes aspectos materializaram-se em resultados na pauta da disciplina, que é ofertada apenas uma vez ao ano em cada turno (noturno e matutino, turmas de diferentes perfis) e na qual se pode perceber a redução das reprovações e aumento da média das turmas após a implementação do projeto.

As figuras 2 a 5 ilustram parte dos resultados obtidos com a aplicação da nova metodologia. 

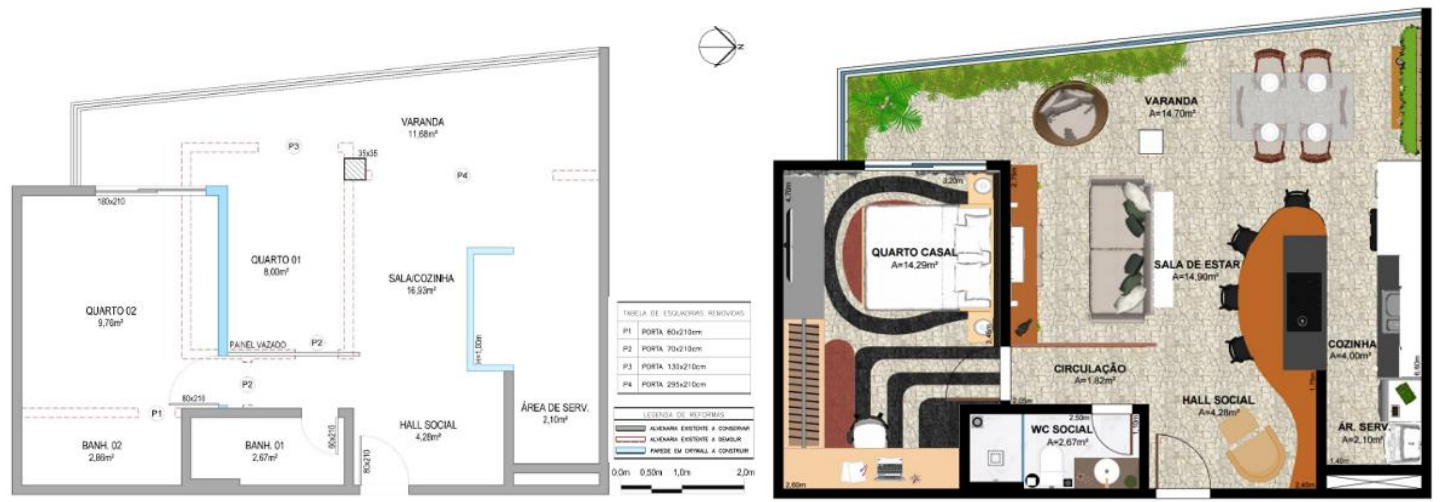

Figura 2 - exemplos de projetos técnicos desenvolvidos por alunos - Projeto 01

Fonte: Alunas Tayná Mozine e Milena Bastos. Grupo fechado da disciplina no Facebook
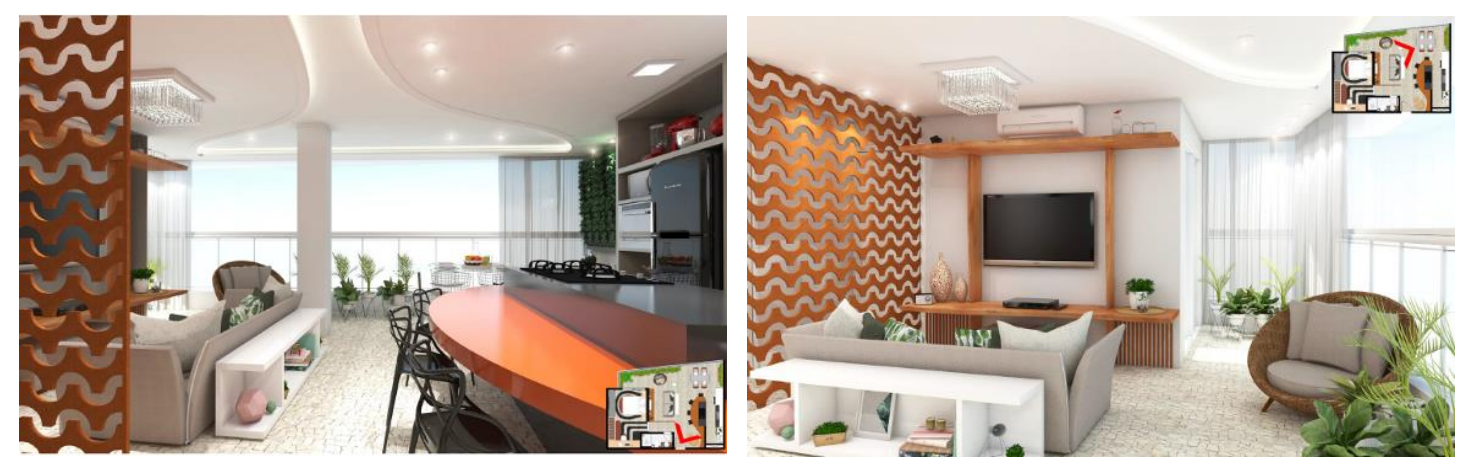

Figura 3 - exemplos de imagens renderizadas em 3D do projeto finalizado - Projeto 01 Fonte: Alunas Tayná Mozine e Milena Bastos. Grupo fechado da disciplina no Facebook
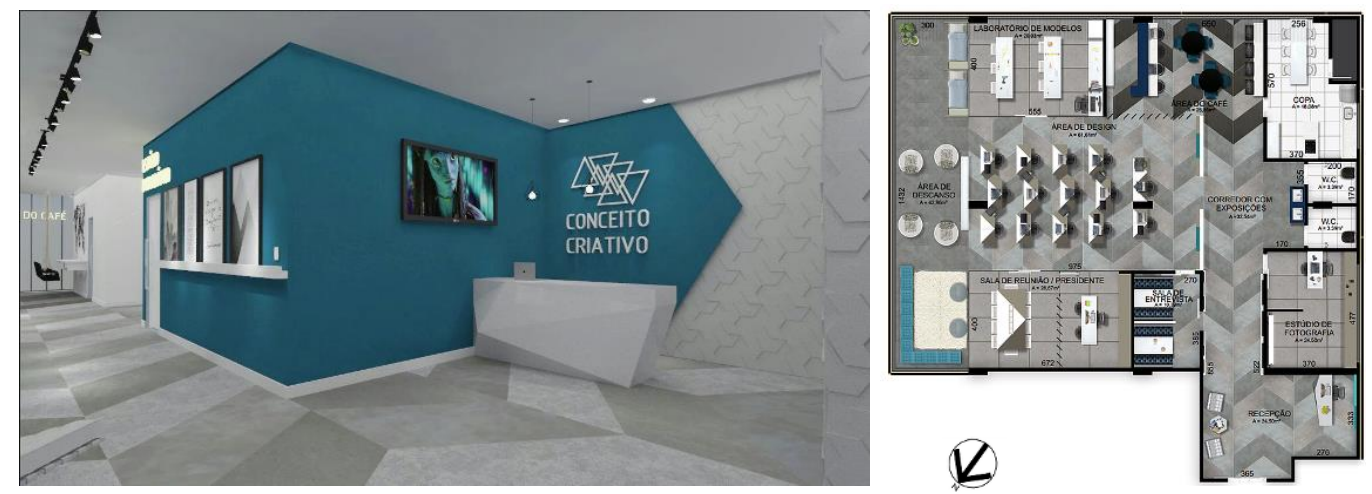

Figura 4 - exemplos de projetos desenvolvidos por alunos - Projeto 02

Fonte: Alunos Brunna Pauli e Gabriel Freitas. Grupo fechado da disciplina no Facebook
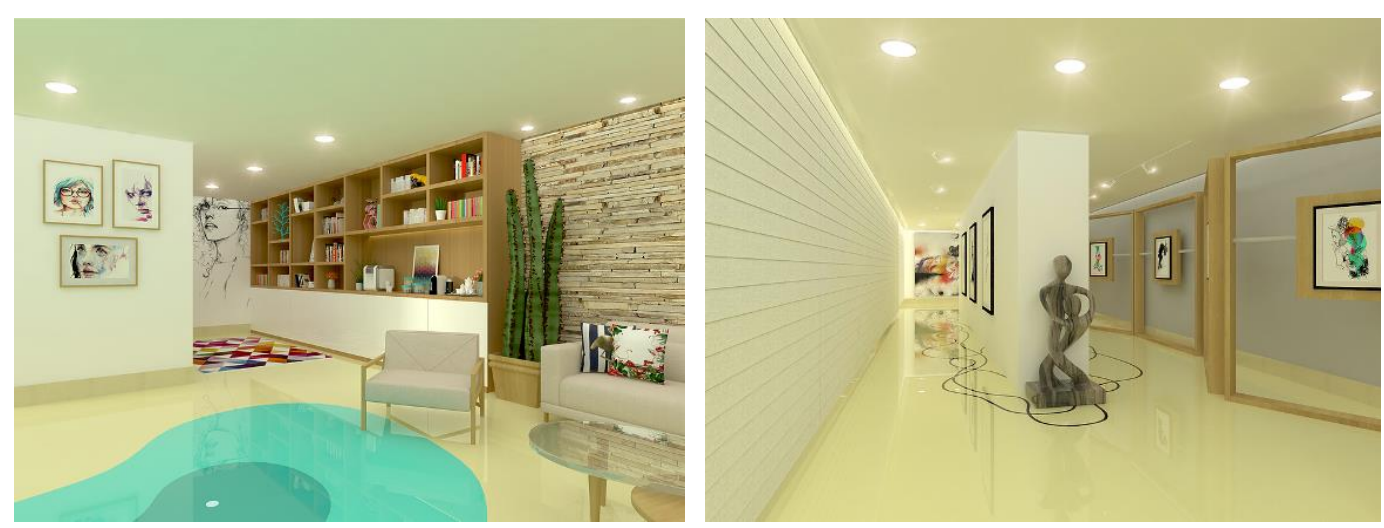

Figura 5 - exemplos de projetos desenvolvidos por alunos - Projeto 02 Fonte: Alunas Bianca Afonso e Iolanda Luz. Grupo fechado da disciplina no Facebook 


\section{CONSIDERAÇÕES FINAIS}

Novas experiências e estratégias tem sido desenvolvidas e testadas no sentido de buscar aprimoramento da metodologia da disciplina e favorecer a transdisciplinaridade e o uso de ferramentas computacionais. Uma delas diz respeito à introdução do uso de programas de simulação da iluminação artificial como apoio à definição dos projetos luminotécnicos no projeto de espaços de trabalho, entretanto, os resultados dessa experiência ainda não são conclusivos.

A partir da aplicação da metodologia pôde-se perceber que a proposta de sala de aula invertida e metodologias ativas, bem como o uso das tecnologias de informação e comunicação como recurso educacional podem favorecer o ensino de projeto, entre outros processos educativos, desde que todos os componentes desse processo estejam engajados.

Pode-se afirmar que a sala de aula invertida permite inovar e aprimorar 0 processo de construção do conhecimento, em que o aluno passa a ser ativo no processo de aprendizagem. $O$ ensino deixa de ser centrado na sala de aula e na figura do professor, invertendo a organização do modelo tradicional, e passa a ser o mediador da aprendizagem, concentrando o maior tempo em sala para orientação.

A proposta de criação do grupo no Facebook, sites de portfólio e a inclusão da figura do cliente mantém o aluno engajado a obter bons resultados. Nos últimos semestres, entretanto, tem-se discutido a efetividade e a provável redução do prazo em que ainda será viável a utilização do grupo do Facebook, pois nota-se que os alunos estão preferindo o uso de outras plataformas para uso como rede social, atualmente consultando o primeiro, sobretudo, como ferramenta em disciplinas.

Melhorias estão em fase de implementação, destacando-se a busca de outras possíveis plataformas e inclusão de novos softwares de simulação de desempenho dos edifícios, o que potencializa a Interdisciplinaridade e amplia o projeto no sentido da transdisciplinaridade.

\section{REFERÊNCIAS}

BRASIL. Ministério da Educação. Resolução n² 2, de 17 de junho de 2010. Institui as Diretrizes Curriculares Nacionais do curso de graduação em Arquitetura e Urbanismo. Disponível em: <http://portal.mec.gov.br/index.php?option=com _docman\&view=download\&alias=5651-rces002-10\&_ategory_slug=junho-2010pdf\&ltemid=30192. Acesso em: 09 mar. 2017.

BRASIL. Instituto Nacional de Pesquisas Educacionais. Portaria $\mathbf{n}^{\circ} 255$, de 02 de junho de 2014. Disponível em: <http://download.inep.gov.br/educacao_ superior/enade/legislacao/2014/formacao_geral/formacao_geral_portaria_n_ 255_02_junho_2014.pdf>. Acesso em: 09 mar. 2017.

MEEL, J. M., Y. REE, H. Como planejar os espaços de escritórios: guia prático para gestores e designers. G. Gilli: Barcelona, 2014.

SUHR, Inge Renate Frose. Desafios no uso da sala de aula invertida no ensino superior. Revista Transmutare, v. 1, n. 1, 2016. 